\title{
Ortaokul Matematik Öğretmenlerinin Manipülatif Kullanımına İlişkin Tutumlarının ve İhtiyaçlarının İncelenmesi
}

\author{
DOI: 10.26466/opus.525024 \\ * \\ Hatice Cetin $^{*}-$ Serhat Aydın ${ }^{* *}$ - Murat İbrahim Yazar ${ }^{* * *}$ \\ * Dr. Öğr. Üyesi, Necmettin Erbakan Üni. Ahmet Keleşoğlu Eğitim Fakültesi, Konya / Türkiye \\ E-Posta: haticebts@gmail.com \\ ORCID: 0000-0003-0686-8049 \\ ** Dr. Öğr. Üyesi, Karamanoğlu Mehmetbey Üniversitesi, Eğitim Fakültesi, Karaman / Türkiye \\ E-Posta: aydins@kmu.edu.tr \\ ORCID: 0000-0003-4341-2913 \\ *** Dr. Öğr. Üyesi, Karamanoğlu Mehmetbey Üniversitesi, Eğitim Fakültesi, Karaman / Türkiye \\ E-Posta: myazar@kmu.edu.tr \\ ORCID: 0000-0002-3259-2552
}

Öz

Bu çalışmada, ortaokul matematik öğretmenlerinin matematik derslerinde somut ve sanal manipülatif kullanımına ilişkin tutumlarının farklı değişkenler açısından incelenmesi ayrıca manipülatif kullanma ile ilgili ihtiyaçlarının belirlenmesi amaçlanmaktadır. Çalışmanın araştırma yöntemi tarama modelidir. Katılımcılar, farklı illerde görev yapan 152 ortaokul matematik öğretmeninden oluşmaktadır. Veri toplama aracı olarak, öğretmenlerin manipülatif kullanımına ilişkin tutumlarını belirlemek amacıyla Matematik Derslerinde Manipülatif Kullanımına ilişkin Tutum (MDMKİT) ölçeği kullanılmıştır. Ölçek, beş maddeden oluşan tek faktörlü bir yapıdadır. Veriler, betimsel ve anlam çıkartıcı istatistik yoluyla analiz edilmiştir. Verilerin normallik analizi yapılarak normal dağılım gösterdiğgi görüllmüş̧ür. Bu nedenle, $t$ testi (ilişkisiz örneklemler için $t$ testi), F testi (ilişkisiz örneklemler için iki faktörlü ANOVA) yapılarak problem cümlelerine yanıt aranmıştır. Yapılan analizler sonucunda elde edilen bulgular neticesinde, öğretmenlerin \% 65,8'i manipülatif kullandiklarını belirtmişlerdir. Öğretmenler, en çok Sayılar ve İşlemler öğrenme alanında-Tamsayılar ve Kesirler alt öğrenme alanında $(\% 30,2)$, daha sonra Geometri ve Ölçme öğrenme alanında- Geometrik Cisimler alt öğrenme alanında $(\% 24,6)$ ve Cebir öğrenme alanında Cebirsel İfadeler - Eşitlik Denklem alt öğrenme alanlarında $(\% 8,7)$ somut ve sanal manipülatiflere ihtiyaç duyduklarını ifade etmişlerdir. Bununla birlikte, öğretmenlerin hizmet içi eğitim alma durumlarına göre manipülatif kullanma ile ilgili tutumları arasında manidar bir fark saptanmamıştır ( $t=.503, p>$.05). Ortaokul matematik öğretmenlerinin görev yeri ve kıdem yılı değişkenlerinin ortaokul matematik öğretmenlerinin manipülatif ile ilgili tutumlarm etkileyen bir faktör olarak bulunmamıştır $\left(F_{140}=.667 ; p>.05\right)$

Anahtar Kelimeler: Manipülatif, ortaokul, tutum, matematik eğitimi, matematik öğretmeni. 


\title{
Investigation of Attitudes and Needs of Manipulative Use of Middle School Mathematics Teachers
}

\begin{abstract}
In this study, it is aimed to investigate the attitudes of middle school mathematics teachers regarding concrete and virtual manipulative use in terms of different variables and also to determine their needs related to manipulative use. The research method of the study is the survey model. Participants consisted of 152 middle school mathematics teachers working in different provinces. In order to determine the attitudes of the teachers towards manipulative use, Attitude towards Manipulative Use in Mathematics Courses (ATMUMC) scale was used. The scale has a single factor structure consisting of five items. Data were analyzed by descriptive and meaningful statistics. Normal analysis of the data was performed by making normality analysis. For this reason, $t$ test ( $t$ test for independent samples), F test (two-factor ANOVA for independent samples) were searched for problem sentences. As a result of the analyses, $65.8 \%$ of teachers stated that they used manipulative. Teachers in the subject of the most Numbers and Operations- Integers and Fractions (30.2\%), then in the field of Geometry and Measurement learning - Geometrical Objects (24.6\%) and Algebra - Equation (8.7\%) stated that they needed concrete and virtual manipulatives. In additon, there was no significant difference between the attitudes of the teachers regarding the use of manipulative according to their in-service training status $(t=.503, p>.05)$. It was not found that middle school mathematics teachers' place of duty and seniority year variables with the middle school mathematics teachers' attitudes towards manipulative $\left(F_{140}=.667 ; p>.05\right)$
\end{abstract}

Keywords: Manipulative, middle school, attitude, mathematics education, mathematics teacher. 


\section{Giriş}

Matematik manipülatifleri, matematiksel kavramları içeren, çeşitli duyulara hitap eden ve öğrenciler tarafından dokunup hareket ettirilebilen somut modeller (Hynes, 1986) veya birey tarafından bilinçli ve bilinçsiz matematiksel düşüncenin teşvik edileceği duyusal bir şekilde ele alınabilen nesneler (Swan ve Marshall, 2010) olarak tanımlanabilir. Matematiksel bilgiyi oluşturmak için fırsatlar sunan dinamik bir nesnenin etkileşimli, Web tabanlı görsel temsili olarak tanımlanan sanal manipülatifler (Moyer, Bolyard, ve Spikell, 2002) de matematik manipülatifleridir.

Ulusal Matematik Öğretmenleri Konseyi, matematik öğretiminde manipülatifleri, süreç standartlarından biri olarak temsil (representation) temasında göstermektedir (NCTM, 2000). Bu bağlamda manipülatiflerin matematik eğitiminde öğretimsel araç- model olarak kullanılması önemlidir. Yapılan araştırmalar somut materyallerin ve sanal öğrenme nesnelerinin derslerde ihtiyaç duyulan nesneler olduğunu göstermektedir (Bohan ve Shawaker, 1994; Clements ve McMillen, 1996; Kelly, 2006; Mutluoğlu ve Erdoğan, 2017; Ross ve Kurtz, 1993). Eğitim araştırmaları, manipülatifler pratik olarak uygulandığında öğrencilerin, kendileri için matematiksel bir anlayış geliştirmeye başladıklarını ve bunun da paha biçilmez bir öğrenme deneyimi sağladığını göstermiştir (Boggan, Harper, ve Whitmire, 2010). Öte yandan, somut nesnelerle birlikte sanal manipülatifler de bilgisayar ortamında özellikle bazı soyut kavramların modellenerek somutlaştırılmasıyla, somut algılama düzeyinde olduğu düşünülen öğrencilerin; kavramları daha iyi anlama, kavramlar hakkında yorum yapabilme ve kavramları problem çözmede kullanabilme yeteneklerini geliştirmelerinde yardımcı olduğu (Durmuş ve Karakirik, 2006; Ross, 2008), öğrencilerin matematiksel düşünme becerilerinde olumlu değişiklikler yaptığı (Kılıç ve Tunç-Pekkan, 2013), başarıyı arttırdığı (Tutak, Aydoğdu ve Erşen,2014) belirtilmektedir. Nitekim, manipülatiflerin uzun süreli kullanımının başarıyı arttırdığı 60 çalışmanın incelendiği metanaliz çalışması ile ortaya konmuştur (Sowell, 1989).

Kısaca, manipülatiflerin kullanımı, okullardaki öğrenciler için matematiğin öğretilmesi ve öğrenilmesini kolaylaştırabilir (Baki, Kosa, ve Guven, 2011). Öğretim stratejileriyle ilgili olarak, manipülatiflerin kulla- 
nımı, matematik öğretmenliği yeterliliği en yüksek dereceye sahip öğretmen adayları tarafından güçlü bir şekilde benimsenmiştir (Swars, 2005). Bu yüzden, matematik öğretmenleri ve adayları bu materyalleri nasıl kullanacaklarını öğrenmelidir (Çakıroğlu ve Tuncay, 2007).

Yapılan görüşmelerle, öğretmenlerin büyük çoğunluğunun öğretim yazılımları ile ilgili olumlu düşündükleri (Aydoğmuş, 2010; Kutluca ve Birgin, 2007; Önal ve Çakir, 2016) ancak yeterli bilgi sahibi olmadıkları ortaya çıkarılmıştır (Aydoğmuş, 2010; Çakıroğlu ve Tuncay, 2007; Önal ve Çakir, 2016). Yine, sınıf öğretmen adaylarının çoğu materyal kullanımı konusunda olumlu görüşlere sahip olduğunu; ancak materyallerin matematik kavramlarını anlamaya nasıl yardımcı olabildiği üzerinde çok da net fikirleri olmadığ1 belirtilmiştir (Özdemir, 2008). Gökmen vd. (2016) tarafından yapılan çalışmada ise, sınıf ve ortaokul matematik öğretmenlerinin materyal kullanmaya yönelik yeterlik inançları yüksek olmasına rağmen, derslerinde materyal kullanma düzeyleri ile yeterlik inançları arasında anlamlı bir ilişki bulunmamıştır. Öğretmenlerin manipülatif kullanımı ile ilgili tutumlarının incelendiği çalışmalarda öğretmenlerin manipülatif kullanımıyla ilgili özgüvenlerinin hayli yüksek olduğu (Mcintosh, 2013) bulguları mevcuttur. Yapılan bir başka çalışmada da ortaokul ve lise matematik öğretmenlerinin çoğunluğunun matematik derslerinde somut materyal kullanilması konusunda olumlu tutum sergilediği ve öz-yeterliklerinin yüksek olduğu tespit edilmştir (Yazlık, 2018). Birçok öğretmen, manipülatifleri derslerinde kullanmakta ve kendilerini rahat hissetmekte ancak birçoğu yeterli hizmet öncesi veya hizmet içi eğitim almamaktadır (Mcintosh, 2013). Öğretmenlerin sınıflarında manipülatif kullanmamalarının eğitim eksikliği ile ilişkili olduğu belrtilmektedir (Mcintosh, 2013).

Manipülatif kullanımının vakit aldığı ve hazırlanmasının zor olduğu ile ilgili öğretmen ve öğretmen adaylarının olumsuz görüşlerine de rastlanmaktadır (Johnson, 1993; Ünlü, 2017). Bu fikre büyük ölçüde katılmayan öğretmenlerin ortaya çıkarıldığı bir çalışma Mcintosh'a (2013) ait olan çalışmadır. Bazı materyallerin, bazı konularda modellemede yetersiz kaldığını ortaya çıaran öğretmen görüşleri de vardır. Bununla ilgili olarak örneğin, ortaokul matematik öğretmenleri, sayma pulları ile mo- 
dellemenin somutlaştırma ve tamamlayıcı bir materyal olarak kullanılabileceğini ancak yeterli bir manipülatif olmadığını dile getirmişlerdir (Bozkurt ve Polat, 2011).

Öğretmenlerin materyaller ile ilgili yeterlilk ve görüşlerine ilişkin araştırma sonuçlarının yanında, somut-sanal manipülatifleri kullanma durumlarını, sıklığını ortaya çıkaran çalışmalara da rastlamaktayız. Matematik öğretmen adayları ile yapılan bir çalışmada öğretmen adaylarının büyük bir çoğunluğu öğretmen olduklarında matematik derslerinde materyal kullanmayı düşündüklerini belirtmişlerdir (Ünlü, 2017). Materyal kullanmayı isteme nedenleri materyallerin öğretimi kolaylaştırması, duyuşsal alana yönelik kazanımlar vb. nedenlerle açıklanırken en çok geometri konularının öğretiminde materyal kullanma gereksinimlerinden bahsedilmiştir (Ünlü, 2017).

Manipülatif kulanmının üst kademelere göre alt sınıflarda kullanımının daha uygun oluğu (Uribe-Flórez ve Wilkins, 2017; Mcintosh, 2013), ile ilgili öğretmen görüşleri vardır. Diğer yandan Johnson (1993) tarafından yapılan çalışmada öğretmenlerin çoğu manipülatif kullanımının tüm ilköğretim sınıflarındaki çocuklar için güçlü bir matematiksel temel oluşturmaya yardımcı olabileceğine inanmaktadır. Gilbert ve Bush (1988) tarafından yapılan çalışmada, deneyimli öğretmenlerin deneyimsiz öğretmenelre göre manipülatifleri daha az kullandıkları belirtilmiştir. Bunun aksine kıdem arttıkça manipülatif kullanımını arttığ 1 ile ilgili bulgular da mevcuttur (Mcintosh, 2013).

Literatürde yukarıda belirtildiği gibi, manipülatif kullanımı ile ilgili öğretmen adayları ve öğretmenlerle yapılan çalışmalara rastlanmaktadır. Ancak çalışmalar, genellikle betimsel bir istatistikle ya da nitel araştırma desenleriyle yürütülen çalışmalar olarak görülmektedir. Enochs, Smith ve Huinker'den (2000), Bakkaloğlu (2007) tarafından uyarlanan öğretmen adaylarına dönük somut materyal ve sanal öğrenme nesnelerinin kullanımıyla ilgili özyeterlilik ölçeği bulunmaktadır. Diğer yandan manipülatif kullanımına ilişkin tutum anketi (Mcintosh, 2013) öğretmenlerin manipülatifler ile ilgili tutumlarını belirlemek için sunulmuştur. Literatürde manipülatifler ve kullanımı ile ilgili yerli bir tutum ölçeğine rastlanmamaktadır. Aynı zamanda, öğretmenlerin hangi alanda manipülatif gereksiniminin olduğunun belirlenmesi, ihtiyaç ve tercihlerinin bazı faktörlere göre incelenmesi ile ilgili geniş bir çalışmaya ihtiyaç 
duyulmuştur. Çalışma ile, beş maddeden oluşan tek faktörlü beşli likert tipi ölçme aracının geçerlik ve güvenirlik çalışması yapılması suretiyle ilgili ölçme aracından elde edilen veriler kapsamlı bir çalışmanın ürünü olarak sunulacaktır. Bu bağlamda, ortaokul matematik öğretmenlerinin matematik derslerinde somut ve sanal manipülatif kullanımına ilişkin tutumlarının, ayrıca manipülatif kullanma ile ilgili ihtiyaçlarının belirlenmesi amaçlanmaktadır. Bu doğrultuda yanıt aranan problem cümleleri şu şekildedir:

1. Ortaokul matematik öğretmenlerinin manipülatif kullanma durumu nedir?

2. Ortaokul matematik öğretmenleri, hangi konularda manipülatif kullanma ihtiyacı duymaktadır?

3. Ortaokul matematik öğretmenlerinin hizmeti içi eğitim alma durumlarına göre manipülatif kullanımına ilişkin tutumları arasında manidar fark var midır?

4. Ortaokul matematik öğretmenlerinin kıdemlerine göre manipülatif kullanımına ilişkin tutumları arasında manidar fark var midir?

5. Ortaokul matematik öğretmenlerinin görev yerine göre manipülatif kullanımına ilişkin tutumları arasında manidar fark var midir?

6. Ortaokul matematik öğretmenlerinin manipülatif kullanımına ilişkin tutumları kıdem ve görev yeri değişkeni ortak etkisine göre anlamlı bir şekilde farklılaşmakta mıdır?

\section{Yöntem}

\section{Araştırmanın modeli}

Çalışma, tarama modelinde yürütülmüştür. Bir grubun belirli özelliklerini için verilerin toplanmasını amaçlayan çalışmalara tarama (survey) araştırması denir (Büyüköztürk, 2007). Araştırmada ayrıca öğretmenlerin manipülatif kullanımına ilişkin tutumlarını belirlemek amacıyla Matematik Derslerinde Manipülatif Kullanımına ilişkin Tutum (MDMKİT) ölçeği geliştirilmiştir. 


\section{Çalışma Grubu}

Katılımcılar, farklı illerin farklı yerleşim bölgelerinde görev yapan 152 ortaokul matematik öğretmeninden oluşmaktadır. Katılımcıların özellikleri Tablo 1 ve Tablo 2'de verilmiştir.

Tablo 1. Katılımcıların Görev Yerlerine Göre Dă̆ılımı

\begin{tabular}{ccc}
\hline Görev yeri & $\mathbf{f}$ & $\mathbf{\%}$ \\
\hline Köy-kasaba & 12 & 7.9 \\
İlçe & 32 & 21.1 \\
İl & 108 & 71.1 \\
\hline Toplam & 152 & 100 \\
\hline
\end{tabular}

Tablo 1'e göre, araştırmaya katılan 152 ortaokul matematik öğretmeninin 12'si (\%7.9) köy ya da kasabada, 32'si (\%21.1) ilçede, 108'i (\%71.1) il merkezinde görev yapmaktadır. Buna göre katılımcıların yarısından fazlasının (\%71.1) merkez okullarda çalıştığı görülmektedir.

Tablo 2. Katılımcıların Kıdem Yılına Göre Dağılımı

\begin{tabular}{ccc}
\hline Kidem y1lı & f & \% \\
\hline $1-5$ & 44 & 28.9 \\
$6-10$ & 40 & 26.3 \\
$11-15$ & 40 & 26.3 \\
$16-20$ & 24 & 15.8 \\
Diğer & 4 & 2.6 \\
\hline Toplam & 152 & 100 \\
\hline
\end{tabular}

Tablo 2'ye göre, araştırmaya katılan 152 ortaokul matematik öğretmeninin 44'ü (\%28.9) 1-5 yılları arasında, 40'1 (\%26.3) 6-10 yıl arasında, 40'1 (\%26.3) 11-15 yıl arasında, 24'ü (15.8) 16-20 yıl arasında ve 4'ü (\%2.6) 20 yılın üzerinde çalıştıkları görülmektedir. Katılımcıların çoğunun (\%54.7) mesleğin ilk yıllarında olduğu söylenebilir. 


\section{Veri Toplama Aracı}

Veriler öğretmenlerin manipülatif kullanımına ilişkin tutumlarını belirlemek amaciyla geliştirilen Matematik Derslerinde Manipülatif Kullanımına İlişkin Tutum(MDMKITT) ölçeği kullanılarak toplanmıştır. Ölçeğin geliştirilmesinde önce ilgili alan yazın taranmıştır. Daha sonra alan yazına uygun şekilde bir madde havuzu oluşturulmuştur. Bu madde havuzu uzman incelemesine tabii tutulmuş ve uzmanlar tarafından uygun görülen maddeleri kullanarak uygulama yapılmıştır. Bu uygulama sonucunda elde edilen veri setinin faktör analizlerine uygunluğu araştırılmıştır. Bu amaçla uygulamadan elde edilen veri seti üzerinde Aydın (2016) tarafından önerilen şekilde: (a) Veri setinin faktör analizlerine uygunluğunun incelenmesi, (b) Açımlayıcı faktör analizlerinin yapılması ve yorumlanması, (c) Güvenirlik analizleri yapılmıştır.

Uygulamadan elde edilen veri setinin faktör analizlerine uygunluğunu görmek amacıyla sırasıyla normallik testleri yapılmış eldeki verinin çarpıklık ve basıklık katsayılarının -1 ve +1 aralığında bulunduğu dolayısıyla normal dağılım gösterdiği görülmüştür. Daha sonra veri içerisinde kayıp ve uç değerlerin varlığı araştıılmış ve kayıp ve uç değerlerin bulunmadığı görülmüştür. Bundan sonra maddeler arası madde-madde ve ters-imaj korelasyon matrisleri incelenmiştir. Bu incelemede maddemadde korelasyonlarının tamamı yeterli $(R>0.3)$ ve istatistiksel açıdan anlamlı $(\mathrm{p}<.05)$ olduğu için bu aşamada çıkartılması gereken madde bulunmamıştır. Daha sonra örneklem büyüklügünün faktör analizine uygunluğu incelenmiştir. Burada N=152 kişilik örneklemin katılımcı sayısı bakımından yeterli düzeyde olduğu (Comrey ve Lee, 2013), katılımc1 sayısı - madde sayısı oranı bakımından da madde sayısı olan beşin, beş veya onla çarpılmasından elde edilen 25 ve 50 sayılarından büyük olması nedeniyle yine yeterli olduğu (Bryman ve Cramer, 2001) ve son olarak da KMO testinin sonucu 0.70 bulunarak orta düzeyde yeterli olduğu ve Bartlett küresellik testi sonucunda küresellik problemi olmadığı $(\mathrm{p}<0.05)$ görülmektedir (Şencan, 2005). Son olarak çoklu doğrusallık ( $R>0.9)$ ve tekillik $(R=1)$ problemlerinin varlığı araştırılmış ve maddeler arası korelasyon katsayılarının 0.3 ve 0.6 arasında değiştiği için bu problemlerin bulunmadığı gösterilmiştir. 
Faktör analizlerinin yapılması sonucu beş maddeden oluşan ölçeğin tamamı tek bir faktör altında toplanmakta ve tek faktör toplam varyansın \% 45'ini açılayabilmektedir. Açıklanan varyans miktarı bakımından ölçeğin tek faktörlü yapıda kullanılabileceğini söylemek mümkündür (Şekercioğlu, 2009). Tek faktörlü yapıda ölçeğe ait maddelerin yük değerleri .63 ve .74 arasında değişmektedir. Maddelerin yük değerlerinin en az 0.40 olması ölçütü dikkate alındığında tek faktörlü yap1 doğrulanmaktadır (Beavers et al., 2013). Bu bulgular dışında Kaiser'in birden büyük özdeğer kuralı, Cartell'in yamaç birikinti grafiği yöntemi, Velicer'in MAP testi ve Horn'un paralel analizi de uygulandığı zaman ölçeğin tek faktörlü yapıda olduğu doğrulanmıştır.

Güvenirlik analizleri için iç tutarlılık göstergesi olarak Cronbach alfa ve Mc Donald omega katsayılarına bakılmıştır. Bu testlerin sonucunda alfa katsayısı .70 ve omega katsayısı .74 olarak bulunmuştur. Bu değerler ilgili alanyazın bağlamında iç tutarlılığın yeterli olduğunu ortaya koymaktadır (Büyüköztürk, 2007).

Özet olarak öğretmenlerin manipülatif kullanımına ilişkin tutumlarını belirlemek amacıyla geliştirilen Matematik Derslerinde Manipülatif Kullanımına İlişkin Tutum (MDMKIT) ölçeğinin tek faktörlü yapıda olduğu ve bu şekilde kullanılmasının geçerli ve güvenilir sonuçlar verdiği ortaya konulmuştur.

Ayrıca, öğretmenlerin matematik derslerinde en çok hangi konuda manipülatife ihtiyaç duyduklarını belirlemek için bir açık uçlu maddeden yararlanılmıştır.

\section{Verilerin Analizi}

Veriler, betimleyici ve anlam çıkartıcı istatistik yoluyla analiz edilmiştir. Tanımlayıcı istatistik sayısal verileri sınıflama ve özetlemede kullanılan yordamlardır ve verileri tablo, grafik veya sayısal olarak anlamlı bir biçimde özetler. Bazı veriler frekans dağılımı olarak düzenlenebilir (Tütek ve Gümüşoğlu, 2008). Öğretmenlerin verdikleri yanıtlar, detaylı bir şekilde betimleyici istatistik yoluyla açılanmıştır. Yine, öğretmenlerin en çok hangi konuda manipülatif kullanımına ihtiyaç duydukları da (açık uçlu madde olduğundan) frekans ve yüzde değerleriyle sunulmuştur. 
Anlam çıkartıcı istatistik kısmıyla ilgili fark analizi doğrultusunda, verilerin normallik analizi yapılmış ve verilerin normal dağılım gösterdiği görülmüştür. Bu nedenle, parametrik testler; $t$ testi (ilişkisiz örneklemler için $\mathrm{t}$ testi), $\mathrm{F}$ testi (ilişkisiz örneklemler için iki faktörlü ANOVA) yapılarak problem cümlelerine yanıt aranmaya çalışılmıştır. Anlam çıartıcı istatistik, gözlemlenmiş durumlardan elde edilen verilerle, gözlemlenmemiş durumlar için sonuç çıkarır ve popülasyon hakkında öngörüleme yapar (Tütek ve Gümüşoğlu, 2008).

\section{Bulgular}

“Ortaokul matematik öğretmenlerinin manipülatif kullanma durumu nedir?" problem cümlesine ait bulgular Tablo 3 'te ve Tablo 4 'te verilmiştir.

Tablo 3. Ortaokul Matematik Öğgretmenlerinin Manipullatif Kullanımına İlişkin Verdikleri Yanitlar

\begin{tabular}{ccc}
\hline Manp. kullanma & f & \% \\
\hline Evet & 100 & 65.8 \\
Hayır & 52 & 34.2 \\
\hline Total & 152 & 100 \\
\hline
\end{tabular}

Tablo 3'e göre, öğretmenlerin 100 'ü (\%65.8) manipülatif kullandıklarını, 52'si (\%34.2) manipülatif kullanmadıklarını belirtmişlerdir.

Yapılan araştırma ile ortaokul matematik öğretmenlerinin ankette yer alan sorulara cevap dağılımı Tablo 4 'te verilmiştir.

Tablo 4'e göre, manipülatif kullanımının bütün ilköğretim sınıf (1-8. sinıf) düzeyine uygun olduğu görüşüne güçlü bir şekilde katılanlar çalışma grubunun \%33.6'sını oluşturmaktadır. Bu görüşe kesinlikle katılmayanlar ise katılımcıların \%3.9'unu oluşturmaktadır. Bir diğer olumlu madde olan matematik kavramlarının manipülatiflerle etkili ve eğlenceli olarak öğretileceğine ilişkin net olumlu görüş bildirenlerin \%44.1 olduğu görülmektedir. Bu görüşe kesinlikle katılmadığını belirten öğretmenler ise katılımcların \%2'sini oluşturmaktadır. 
Tablo 4. Ortaokul Matematik Öğretmenlerinin Manipülatif Kullanımına İlişkin Verdikleri Yantlar

\begin{tabular}{|c|c|c|c|c|c|c|c|c|c|c|}
\hline & \multicolumn{2}{|c|}{$\begin{array}{c}\text { Kesinlikle } \\
\text { Katılmıyoru } \\
\text { m }\end{array}$} & \multicolumn{2}{|c|}{$\begin{array}{c}\text { Katılmiyoru } \\
\mathrm{m}\end{array}$} & \multicolumn{2}{|c|}{$\begin{array}{c}\text { Biraz } \\
\text { Katıliyorum }\end{array}$} & \multicolumn{2}{|c|}{ Katılıyorum } & \multicolumn{2}{|c|}{$\begin{array}{l}\text { Kesinlikle } \\
\text { Kat1liyorum }\end{array}$} \\
\hline & $\mathrm{f}$ & $\%$ & $f$ & $\%$ & $\mathrm{f}$ & $\%$ & $\mathrm{f}$ & $\%$ & $f$ & $\%$ \\
\hline $\begin{array}{l}\text { Manipülatif } \\
\text { kullanımı bütün } \\
\text { sinıf düzeylerine uy- } \\
\text { gundur.(1-8) }\end{array}$ & 6 & 3.9 & 18 & 11.8 & 39 & 25.7 & 38 & 25.0 & 51 & 33.6 \\
\hline $\begin{array}{l}\text { Matematik } \\
\text { derslerinde } \\
\text { manipülatif } \\
\text { kullanmak zordur. }\end{array}$ & 16 & 10.5 & 18 & 11.8 & 53 & 34.9 & 36 & 23.7 & 29 & 19.1 \\
\hline $\begin{array}{l}\text { Matematik } \\
\text { derslerinde } \\
\text { manipülatif } \\
\text { kullanmak çok vakit } \\
\text { alır. }\end{array}$ & 24 & 15.8 & 32 & 21.1 & 50 & 32.9 & 30 & 19.7 & 16 & 10.5 \\
\hline $\begin{array}{l}\text { Mat. kavramları } \\
\text { manipülatif kulla- } \\
\text { narak etkili ve } \\
\text { eğlenceli olarak } \\
\text { öğreteceğimi } \\
\text { düşünüyorum. }\end{array}$ & 3 & 2.0 & 5 & 3.3 & 21 & 13.8 & 56 & 36.8 & 67 & 44.1 \\
\hline $\begin{array}{l}\text { Mat. eğitiminde } \\
\text { manipülatif eğitimi } \\
\text { almak isterim. }\end{array}$ & 6 & 3.9 & 2 & 1.3 & 18 & 11.8 & 45 & 29.6 & 81 & 53.3 \\
\hline
\end{tabular}

Öğretmenlerin bir kısmı, matematik derslerinde manipülatif kullanmanın zor olduğunu (\%19.1) ve çok vakit aldığını (\%10.5) güçlü bir şekilde belirtirken bir kısmı (\%26.3) bu görüşlere kesinlikle katılmamışlardır. Ayrıca, öğretmenler, manipülatif eğitimi almak ile isteklerini "katılıyorum" ifadesi ile (\%29.6), "kesinlikle katılıyorum" ifadesi ile (\%53.3) toplamda (\%82.9) lik bir oranla eğitim almak istediklerini belirtmişlerdir. Genel olarak, ortaokul matematik öğretmenlerinin manipülatif kullanımına ilişkin olumlu tutumlarının olduğu söylenebilir.

“Ortaokul matematik öğretmenleri, hangi konularda manipülatif kullanma ihtiyacı duymaktadır?" problem cümlesine ait bulgular Tablo 5 'te verilmiştir. 
Tablo 5. Ortaokul Matematik Öğretmenlerinin Manipülatif Kullanımına İhtiyaç Duydukları Matematik Konuları

\begin{tabular}{llcc}
\hline Öğrenme Alanı & Konu & f & \% \\
\hline \multirow{5}{*}{ Sayılar ve İşlemler } & Kesirler & 32 & 16.4 \\
& Ondalık Gösterim & 8 & 4.1 \\
& Kümeler & 1 & 0.5 \\
& Tam Sayılar & 27 & 13.8 \\
& Rasyonel Sayılar & 6 & 3 \\
& Üslü İfadeler & 2 & 1 \\
& Kareköklü İfadeler & 2 & 1 \\
\hline \multirow{3}{*}{ Cebir } & Cebirsel İfadeler & 8 & 4.1 \\
& Eşitlik ve Denklemler & 9 & 4.6 \\
& Çarpanlara Ayırma & 2 & 1 \\
\hline \multirow{5}{*}{ Geometri ve Ölçme } & Temel Geo. Kavramlar ve Çizimler & 5 & 2.5 \\
& Üçgenler ve Dörtgenler & 3 & 1.5 \\
& Alan Ölçme & 5 & 2.5 \\
& Geo. Cisimler & 16 & 8.2 \\
& Dönüşüm Geo. & 8 & 4.1 \\
& Çokgenler & 3 & 1.5 \\
& Cisimlerin farklı yönlerden gör. & 3 & 1.5 \\
& Geometri & 32 & 16.4 \\
\hline \multirow{2}{*}{ Diğer } & Soyut konularda & 13 & 6.6 \\
& Her konuda & 10 & 5.1 \\
\hline & Toplam & $\mathbf{1 9 5}$ & $\mathbf{1 0 0}$ \\
\hline
\end{tabular}

Tablo 5'te görüldüğü üzere, öğretmenler, en çok Sayılar ve İşlemler öğrenme alanında, Tam Sayılar ve Kesirler alt öğrenme alanında (\%30.2), daha sonra Geometri ve Ölçme öğrenme alanında- Geometrik Cisimler alt öğrenme alanında (\%24.6) ve Cebir öğrenme alanında Cebirsel İfadeler Eşitlik Denklem alt öğrenme alanlarında (\%8.7) somut ve sanal manipülatiflere ihtiyaç duyduklarını ifade etmişlerdir. Bunlardan hariç olarak soyut konularda, her konuda gibi genel ifade kullananların oranı \%11.7 olarak görülmektedir.

“Öğretmenlerin hizmet içi eğitim alma durumlarına göre manipülatif kullanımına ilişkin tutumları arasında manidar fark var mıdır?" problem cümlesine ait bulgular Tablo 6'da verilmiştir. 
Tablo 6. Ortaokul Matematik Öğretmenlerinin Manipülatif Kullanımına İlişkin Tutumlarının Hizmet İçi Ĕ̆itim Alma Değişkenine Göre t testi Sonuçları

\begin{tabular}{llllll}
\hline & $\mathbf{N}$ & $\overline{\boldsymbol{X}}$ & $\mathbf{s s}$ & $\mathbf{t}$ & $\mathbf{p}$ \\
\hline Evet & 31 & 21.322 & 3.936 & \multirow{2}{*}{.503} & \multirow{2}{*}{.615} \\
Hayır & 121 & 20.917 & 4.013 & & \\
\hline
\end{tabular}

Tablo 6'da görüldüğü üzere, ortaokul matematik öğretmenlerinin matematik derslerinde manipülatif kullanımına ilişkin tutumlarının hizmet içi eğitim alma durumuna göre anlamlı olarak farklılaşıp farklılaşmadığını belirlemek için yapılan bağımsız örneklemler $t$ testi sonucunda ortalamalar arasındaki farkın anlamlı olmadığı bulunmuştur $\left(t_{150}=.503 ; \mathrm{p}>.05\right)$. Buna göre öğretmenlerin hizmet içi eğitim alma durumları, ortaokul matematik öğretmenlerinin matematik derslerinde manipülatif kullanma ile ilgili tutumlarını etkileyen bir faktör olmadığı söylenebilir.

“Ortaokul matematik öğretmenlerinin kıdemlerine göre manipülatif kullanımına ilişkin tutumları arasında manidar fark var mıdır?", Öğretmenlerin görev yerine göre manipülatif kullanımına ilişkin tutumları arasında manidar fark var mıdır?" ve "Öğretmenlerin manipülatif kullanımına ilişkin tutumları kıdem ve görev yeri değişkeni ortak etkisine göre anlamlı bir şekilde farklılaşmakta mıdır?" problem cümle-lerine ait bulgular Tablo 7'de verilmiştir.

Tablo 7. Ortaokul Matematik Öğretmenlerinin Manipülatif Kullanımına İlişkin Tutumlarının Kıdem ve Görev Yeri Değişkenine Göre İki Faktörlï Anova Sonuçları

\begin{tabular}{lcccccc}
\hline $\begin{array}{c}\text { Varyansın } \\
\text { Kaynağ1 }\end{array}$ & $\begin{array}{c}\text { Kareler } \\
\text { Top. }\end{array}$ & Sd & $\begin{array}{c}\text { Kareler } \\
\text { Ort. }\end{array}$ & $\mathbf{F}$ & $\mathbf{p}$ & $\boldsymbol{\eta}^{\mathbf{2}}$ \\
\hline Görev yeri & 27.215 & 2 & 13.608 & 1.185 & .309 & .017 \\
Kidem & 99.396 & 4 & 24.849 & 2.164 & .076 & .058 \\
Görev & 38.327 & 5 & 7.665 & .667 & .649 & .023 \\
$\begin{array}{l}\text { yeriK1dem } \\
\text { Hata }\end{array}$ & 1607.975 & & & & & \\
\hline
\end{tabular}

Tablo 7 incelendiğinde, görev yerinin $\left(F_{140}=1.185 ; \mathrm{p}>.05\right)$ ve k1dem yılının $\left(F_{140}=2.164 ; \mathrm{p}>.05\right)$, ortaokul matematik öğretmenlerinin matematik derslerinde manipülatif kullanma ile ilgili tutumlarının üzerindeki ayrı etkilerinin ve görev yeri*kı1dem yılı ortak etkilerinin $\left(F_{140}=.667\right.$; p>.05) anlamlı olmadığı bulunmuştur. Buna göre, görev yeri ve kıdem yılı 
hem ayrı ayrı olarak hem de birlikte ortaokul matematik öğretmenlerinin manipülatif ile ilgili tutumlarını etkileyen bir faktör olarak bulunmamıştır denilebilir.

\section{Tartışma, Sonuç ve Öneriler}

Araştırmada, ortaokul matematik öğretmenlerinin manipülatif kullanma ile ilgili görüş ve tutumlarını incelemek amacıyla bir ölçme aracı olarak tek faktörlü olarak geliştirilen Matematik Derslerinde Manipülatif Kullanımına İlişkin Tutum (MDMKİT) ölçeği kullanılmıştır.

$\mathrm{Bu}$ çalışma ile, ortaokul matematik öğretmenlerinin \%65.8 oranında manipülatif kullandıkları ve genel anlamda manipülatif kullanımına ilişkin olumlu görüş belirttikleri tespit edilmiştir. Bununla tutarlı olarak, literatürde; öğretmen adayları ve öğretmenlerin manipülatif kullanımına ilişkin rahat davrandıkları, olumlu gorüşe sahip oldukları (Özdemir, 2008; Mcintosh, 2013; Aydoğdu İskenderoğlu, Türk ve İskenderoğlu, 2016; Yazlık, 2018) ve matematik öğretmenlerinin yeterlik inançları yüksek olduğu ile ilgili bulgulara (Gökmen vd. (2016; Yazlık, 2018) rastlanmaktadır. Manipülatif kulanımının ilköğretimde bütün sınıf düzeylerine (1-8) uygun olduğunu güçlü bir şekilde belirten öğretmenlerin \%33.6 oranında olduğu görülmektedir. Bundan farklı olarak literatürde, manipülatif kulanımının alt sınıflarda daha uygun olduğu ile ilgili öğretmen görüşlerine rastlanmaktadır (Uribe-Flórez ve Wilkins, 2017; Mcintosh, 2013).

Araştırmada, manipülatif kullanmanın zor olduğu ve vakit aldığı ile ilgili öğretmen görüşleri de mevcuttur. Bu bulgularla Johnson'a (1993) ve Ünlü'ye ait (2017) çalışma bulgularının tutarlı olduğu söylenebilir.

Matematik öğretmenlerinin manipülatif kullanımına ilişkin tutumlarının hizmet içi eğitim alma değişkenine göre anlamlı bir farklılık göstermediği görülmüştür. Yine, kıdem ve görev yeri değişkenine göre de anlamlı bir fark bulunamamıştır. Literatür incelendiğinde, kıdem değişkenine yönelik sonuçların tutarlı olmadığı görülmektedir. Deneyimli öğretmenlerin deneyimsiz öğretmenlere göre manipülatifleri daha az kullandıkları (Gilbert ve Bush, 1988) ile ilgili ve kıdem arttıkça manpulatif kullanımın da arttığı ile ilgili (Mcintosh, 2013) bulgular da mevcuttur. 
Öğretmenler, en çok Sayılar ve İşlemler öğrenme alanında-Tam Sayılar ve Kesirler alt öğrenme alanında (\%30.2), daha sonra Geometri ve Ölçme öğrenme alanında- Geometrik Cisimler alt öğrenme alanında (\%24.6) manipülatif kullanımına ihtiyaç duyduklarını belirtmişlerdir. Buna benzer olarak Ünlü'nün (2017) çalışmasında da öğretmenlerin en çok geometri konularının öğretiminde manipülatif kullanma gereksiniminden bahsetmişlerdir. Yapılan araştırmada öğretmenlerin etkili ve verimli manipülatif kullanımıyla ilgili bir eğitim alma eğiliminde oldukları da belirlenmiştir (kesinlikle katılıyorum, \%53.3).

Yapılan araştırmalar somut materyallerin ve sanal öğrenme nesnelerinin derslerde ihtiyaç duyulan nesneler olduğunu göstermektedir (Bohan ve Shawakwer, 1994; Clements ve McMillen, 1996; Ross ve Kurtz, 1993). Ancak matematik öğretiminde somut materyallerin ve sanal öğrenme nesnelerinin etkili olabilmesi için öğretmenlerin uygun materyalleri ve öğrenme nesnelerini seçebilme ve bunları etkili bir şekilde kullanabilme becerilerine sahip olmaları gerekmektedir. Buna paralel olarak, matematik öğretiminde öğrencilerin müfredat programından yeterince faydalanabilmeleri için materyal kullanımı zaruri olduğu halde, öğretmenlerin bu konudaki bilgi, beceri ve deneyimlerinin yeterli olmamasından ötürü materyal kullanımında zorluk yaşadıkları belirtilmiştir (Bozkurt ve Akalın, 2010).

Bu yüzden, öğretmenlerin hizmet içi eğitim programlarıyla bu konuda desteklenmesi önemlidir. Öğretmenlerle öğretmen yetiştiricilerinin manipülatif kullanma, özellikle de yeni geliştirilen manipülatiflerin kullanımı konusunda gerek hizmet içi eğitimlerle gerekse profesyonel gelişim programlarıyla bir araya gelmeleri önerilmektedir. 
EXTENDED ABSTRACT

\title{
Investigation of Attitudes and Needs of Manipulative Use of Middle School Mathematics Teachers
}

\author{
* \\ Hatice Çetin - Serhat Aydın - Murat İbrahim Yazar \\ Necmettin Erbakan University - Karamanoğlu Mehmetbey University
}

In this study, it is aimed to determine the attitudes of middle school mathematics teachers towards concrete and virtual manipulative use in mathematics courses and also to determine their needs related to manipulative use. The research problems sought in this direction are as follows:1. What is the status of manipulative use of middle school mathematics teachers? 2. In which subjects do mathematics teachers need to use manipulatives? 3. Is there a significant difference between the attitudes of middle school mathematics teachers regarding their manipulative use according to their in-service training? 4 . Is there a significant difference between the attitudes of middle school mathematics teachers towards their seniority? 5. Is there a significant difference between the attitudes of the middle school mathematics teachers towards the place of duty? 6. Are their attitudes towards the manipulative use of middle school mathematics teachers significantly differentiated according to the common effect of seniority and place of duty?

The research method of the study is the survey model. In order to determine the attitudes of the teachers towards manipulative use, Attitude towards Manipulative Use in Mathematics Courses (ATMUMC) scale was used.

Participants consisted of 152 middle school mathematics teachers working in different settlements of different provinces.

The data were collected by using the Attitude towards Manipulative Use in Mathematics Courses (ATMUMC) scale developed to determine the attitudes of the teachers regarding the manipulative use. The suitability of the data set to factor analysis was investigated. It was revealed that 
the Attitude Towards Manipulative Use in Mathematics Courses (ATMUMC) scale which was developed in order to determine the attitudes of teachers about the manipulative use of the teachers was in a single-factor structure and that the use of this method gave valid and reliable results. As a result of the factor analysis, the scale consisting of five items is collected under a single factor and the single factor can account for $45 \%$ of the total variance. It can be said that the scale can be used in a single factor structure in terms of the amount of variance explained. As a result of these tests, the alpha coefficient was .70 and the omega coefficient was found as .74. These values indicate that internal consistency is sufficient in the context of the related literature (Büyüköztürk, 2007).In addition, an openended item was used to determine which teachers needed manipulatives most in mathematics courses.

Data were analyzed by descriptive and semantic statistics. In the direction of the difference analysis related to the meaningful statistical part, the normality analysis of the data was performed and the data showed normal distribution. Therefore, parametric tests ; t-test (t-test for unrelated samples), F-test (two-factor ANOVA for unrelated samples) were used to search for answers to problem sentences.

$100(65.8 \%)$ of the teachers stated that they used manipulatives and 52 $(34.2 \%)$ stated that they did not use manipulatives. 33.6\% of the study group strongly agree that the use of manipulatives is appropriate for the whole primary class (grade 1-8). The participants who do not agree with this opinion constitute $3.9 \%$ of the participants. It is seen that $44.1 \%$ of those who reported a positive opinion about the teaching of mathematical concepts, which are another positive item, would be taught as effective and fun with the qualifications. Some of the teachers stated that it was difficult to use manipulative (19.1\%) and took a long time (10.5\%) in mathematics lessons while some of them $(26.3 \%)$ did not participate in these opinions. In addition, the teachers stated that they wanted to get training regarding manipulative use (in total :82.9\%). In general, it can be said that there are positive attitudes about the manipulative use of middle mathematics teachers. It was found that the difference between the means of the independent samples $t$ test was not significant in order to determine whether the attitudes of the primary mathematics teachers about the manipulative use of mathematics lessons differed according to the status of 
in-service training. $\left(t_{150}=.503 ; \mathrm{p}>.05\right)$. The effects of the duty place $\left(F_{140}=\right.$ $1.185 ; \mathrm{p}>.05)$ and the year of seniority $\left(F_{140}=2.164 ; \mathrm{p}>.05\right)$ on the attitudes of primary mathematics teachers towards manipulative use in mathematics courses and the effects of the place of duty ${ }^{*}$ seniority year $\left(F_{140}=.667\right.$; $\mathrm{p}>$.05). Teachers stated that they needed the use of manipulative in the area of integers and operations (30.2\%), then in Geometry and Measurement Learning - Geometric Objects sub-learning area (24.6\%).

This study show that concrete materials and virtual learning objects are the objects needed in the courses. However, in order for concrete materials and virtual learning objects to be effective in mathematics teaching, teachers should have the ability to select and use the appropriate materials and learning objects effectively. Therefore, it is important that teachers are supported with in-service training programs. It is recommended that teachers and teacher trainers should come together with both in-service trainings and professional development programs in the use of manipulative use, especially in the use of newly developed manipulatives.

\section{Kaynakça / References}

Aydın, S. (2016). More sustainable orientation profiles in beliefs about the nature of mathematics. 14th International JTEFS/BBCC Conference Sustainable Development, Culture, Education Innovations and Challenges of Teacher Education for Sustainable Development. May, 12 - 14, 2016, Konya, TURKEY.

Aydoğdu- İskenderoğlu, T., Türk, Y. ve İskenderoğlu, M. (2016). İlköğretim matematik öğretmeni adaylarının somut materyalleri tanıma-kullanma durumları ve matematik öğretiminde kullanmalarına yönelik özyeterlikleri. Mehmet Akif Ersoy Üniversitesi Eğitim Fakültesi Dergisi,39,1-15.

Aydoğmuş, B. S. (2010). Matematik öğretmenlerinin öğretim yazılımlarından yararlanma konusundaki görüşleri. Yayınlanmamış Yüksek Lisans Tezi, Marmara Üniversitesi, Eğitim Bilimleri Enstitüsü, İstanbul. 
Baki, A., Kosa, T., ve Guven, B. (2011). A comparative study of the effects of using dynamic geometry software and physical manipulatives on the spatial visualisation skills of pre-service mathematics teachers. British Journal of Educational Technology, 42(2), 291-310. https://doi.org/10.1111/j.1467-8535.2009.01012.x

Boggan, M., Harper, S., \& Whitmire, A. (2010). Using manipulatives to teach elementary mathematics. Educational Research, 3, 1-6. Retrieved from http://www.aabri.com/manuscripts/10451.pdf

Bohan, H. J., \& Shawaker, P. B. (1994). Using manipulatives effectively: A drive down rounding road. Arithmetic Teacher, 41(5), 246-249.

Bozkurt, A., ve Polat, M. (2011). Sayma pullariyla modellemenin tam sayılar konusunu öğrenmeye etkisi üzerine öğretmen görüşleri. Gaziantep University Journal of Social Sciences, 10(2), 787-801.

Bozkurt, A. ve Akalın, S. (2010). Matematik öğretiminde materyal geliştirmenin ve kullanımının yeri, önemi ve bu konuda öğretmenin rolü. Dumlupınar Üniversitesi Eğitim Fakültesi Dergisi, 27, 47-56.

Bryman, A., \& Cramer, D. (2001). Quantitative data analysis with SPSS release 10 for Windows. Routledge, New York.

Büyüköztürk, Ş. (2007). Sosyal bilimler için veri analizi el kitabı: Istatistik, araştırma deseni, spss uygulamaları ve yorum. (Yedinci Baskı). Ankara: PEGEM A Yayıncllık.

Comrey, A. L. \& Lee, H. B. (2013). A first course in factor analysis. Routledge, New York.

Çakıroğlu, E., ve Tuncay, B. (2007). Turkish pre-service teachers' views about manipulative use in mathematics teaching: The role of field experience and methods course. In The Enterprise of Education (pp. 275-289).

Clements, D. H., \& McMillen, S. (1996). Rethinking concrete manipulatives. Teaching Children Mathematics, 85(2), 270-279.

Durmuş S., ve Karakirik, E. (2006). Virtual manipulatives in mathematics education - research paper. The Turkish Online Journal of Educational Technology, 5(1), 117-123. Retrieved from http://plaza.ufl.edu/youngdj/talks/vms.htm 
Enochs, L. G., Smith, P. L., \& Huinker, D. (2000). Establishing factorial validity of the mathematics teaching efficacy beliefs instrument. School Science and Mathematics, 100(4), 194-202.

Gilbert, R. K., \& Bush, W. S. (1988). Familiarity, availability, and use of manipulative devices in mathematics at the primary level. School Science and Mathematics, 88(6), 459-469.

Gökmen, A., Budak, A., ve Ertekin, E. (2016). İlköğretim Öğretmenlerinin matematik öğretiminde somut materyal kullanmaya yönelik inançları ve sonuç beklentileri. Kastamonu Education Journal, 24(3), 1213-1228.

Hynes, M. C. (1986). Selection criteria. Arithmetic Teacher, 33(6), 11-13.

Johnson, V. M. (1993). Manipulative materials in mathematics instruction: Addressing teacher reluctance. Retrieved from http://scholarworks.lib.csusb.edu/etdproject\%0Ahttp://scholarworks.lib.csusb. edu/etd-project/636

Kelly, A. C. (2006). Using manipulatives in mathematical problem solving: A performance-based analysis. The Montana Mathematics Enthuasiast, 3(2), 184-193.

Kılıç, H., Pekkan, Z. T., ve Karatoprak, R. (2013). Materyal kullaniminin matematiksel düşünme becerisine etkisi/the effects of using materials on mathematical thinking skills. Eğitimde Kuram ve Uygulama, 9(4), 544-556.

Kutluca, T., ve Birgin, O. (2007). Doğru denklemi konusunda geliştirilen (BDÖ) materyali hakkında matematik öğretmeni adaylarının görüşlerinin değerlendirilmesi (Assessment of Views of Members in Mathematic Teaching on Computer Aided Teaching material developed for Equation of Line). Gazi University, Faculty of Education Journal, 27, 81-97.

Mcintosh, G. V. (2013). Testing Instrumentation validity for measuring teachers' attitudes toward manipulative use in the elementary classroom. The Journal of Infectious Diseases, 208 (10), NP. https://doi.org/10.1093/infdis/jis909.

Moyer, P. S., Bolyard, J. J., \& Spikell, M. A. (2002). What are virtual manipulatives. National Council of Teachers of Mathematics, 8(6), 372-377. https://doi.org/http://dx.doi.org/10.1108/17506200710779521 
Mutluoğlu, A. ve Erdoğan, A. (2017). Ortaokul 6. Sınıf matematik dersi için bir sanal manipülatif takımının geliştirilmesi. II. International Academic Reseach Congress, 19-22 Ekim, Antalya.

National Council of Teachers of Mathematics (Ed.). (2000). Principles and standards for school mathematics (Vol. 1). National Council of Teachers of Mathematics.

Önal, N., ve Çakır, H. (2016). Ortaokul matematik öğretmenlerinin matematik öğretiminde bilişim teknolojileri kullanımına ilişkin görüşleri. Mersin University Journal of the Faculty of Education, 12(1).

Özdemir, E. (2008). Sınıf öğretmeni adaylarının matematik öğretiminde materyal kullanımına ilişkin bilişşel becerileri. Hacettepe Üniversitesi Ĕ̆itim Fakültesi Dergisi, 35(1971), 362-373.

Ross, C. (2008). The effect of mathematical manipulative materials on third grade students' participation, engagement, and academic performance. Master Thesis, University of Central Florida.

Ross, R., \& Kurtz, R. (1993). Making manipulatives work: A strategy for success. Arithmetic Teacher, 40(5), 254-257.

Sowell, E. J. (1989). Effects of manipulative materials in mathematics instruction. Journal for Research in Mathematics Education. https://doi.org/10.2307/749423

Swan, P., \& Marshall, L. (2010). Manipulative materials introduction. Apmc, 15(2), 13-19.

Swars, S. L. (2005). Examining perceptions of mathematics teaching effectiveness among elementary preservice teachers with differing levels of mathematics teacher efficacy. Journal of instructional Psychology, 32(2), 139-148.

Şekercioğlu, G. (2009). Çocuklar için benlik algısı profilinin uyarlanması ve faktör yapısının farklı değişkenlere göre eşitliğinin test edilmesi. Yayınlanmamış Doktora Tezi, Ankara Üniversitesi, Ankara.

Şencan, H. (2005). Sosyal ve davranışsal ölçümlerde güvenilirlik ve geçerlilik. (Birinci Baskı). Ankara: Seçkin Yayınları.

Tutak, T., Aydoğdu, M., ve Erşen, A. N. (2014). Materyal destekli matematik öğretiminin ortaokul 6. sınıf öğrenci başarısına ve tutumuna etkisi. Turkish Journal of Educational Studies, 1(3), 166-185.

Tütek, H., ve Gümüşoğlu, Ş. (2008). İşletme istatistiği. Beta Basım Yayım Dağıtım. 
Ünlü, M. (2017). Pre-Service mathematics teachers ' views about using instructional materials in mathematics lessons. Eğitimde Kuram ve Uygulama Journal of Theory and Practice in Education, 13(1), 10-34.

Uribe-Flórez, L. J., \& Wilkins, J. L. M. (2017). Manipulative use and elementary school students' mathematics learning. International Journal of Science and Mathematics Education, 15(8), 1541-1557. https://doi.org/10.1007/s10763-016-9757-3

Yazlık, D. Ö. (2018). Öğretmenlerin matematik öğretiminde somut öğretim materyali kullanımına yönelik görüşleri. OPUSUluslararası Toplum Araştırmaları Dergisi, 8(15), 775-805. DOI: 10.26466/opus.417200.

\section{Kaynakça Bilgisi / Citation Information}

Çetin, H., Aydın, S. ve Yazar, M. İ. (2019). Ortaokul matematik öğretmenlerinin manipülatif kullanımına ilişkin tutumlarının ve ihtiyaçlarının incelenmesi. OPUS-Uluslararası Toplum Araştırmaları Dergisi , 10(17), 1179-1200. DOI: 10.26466/opus.525024 